\title{
Imigração no Brasil e o processo de escolarização para as crianças e adolescentes imigrantes
}

\begin{abstract}
Resumo: Este artigo apresenta uma investigação de abordagem qualitativa do tipo estado da arte sobre a imigração no Brasil e sua relação com o processo de escolarização da criança e do adolescente imigrante. A pesquisa visa mapear e analisar os resultados das pesquisas acadêmicas, teses e dissertações publicadas nos anos de 2013 a 2018 que abordaram a temática da imigração no Brasil, além de identificar quais destas trataram do processo de escolarização para as crianças e adolescentes imigrantes. Como objeto de análise, foram selecionadas na Biblioteca Digital de Teses e Dissertações 63 pesquisas, que foram analisadas a partir da técnica de Análise de Conteúdo diante da perspectiva de Bardin (2011). Os dados apontam que o imigrante é vítima de racismo, preconceito, xenofobia e estigmas por uma parcela da sociedade receptora e são alvos de exploração de mão de obra, estando por vezes, em situação de escravidão ou análogo à escravidão. Em conseguinte, a falta de políticas públicas e legislações efetivas agravam essa situação. Os dados também revelaram que outra parcela da sociedade receptora estabelece redes de solidariedade e apoio à população imigrante, no acolhimento na nova terra e na orientação de seus direitos. Outrossim, evidencia-se que a valorização do idioma, da cultura e da identidade do imigrante se intensificam após o percurso migratório. Em relação ao processo de escolarização da criança e do adolescente imigrante, o estado da arte revelou restrita produção acadêmica, evidenciando um campo emergente de pesquisa, que proporcione aos imigrantes "vez" e "voz" em seu processo de escolarização.
\end{abstract}

Palavras-chave: imigração; Brasil; escolarização.
Sandra Felicio Roldão Universidade Federal do Paraná (UFPR)

professora.sandraroldao@hotmail. com

Jacques de Lima Ferreira

Universidade Federal do Paraná (UFPR)

drjacqueslima@hotmail.com Veronica Branco

Universidade Federal do Paraná (UFPR)

veronica_branco@hotmail.com

1 Entende-se que a temática da imigração é multifacetada, e cada situação de migração possui suas especificidades, tais como os refugiados e os imigrantes por questões humanitárias. Porém, nesse estudo, trataremos o termo imigrante, conforme descrito na Lei no 13.445 de 24/05/17, "pessoa nacional de outro país ou apátrida que trabalha ou reside e se estabelece temporária ou definitivamente no Brasil". (BRASIL, 2017)

\section{Introdução}

Por que migramos? Por quais motivos os homens e as mulheres deixam sua terra natal e, muitas vezes, sua família, em busca de novos lares em novas terras? Seriam motivados por ideais, por expectativas, por felicidade ou por sonhos? Se a nossa existência é motivada por sonhos (FREIRE, 2014), quais seriam os sonhos propulsores dos imigrantes? ${ }^{1}$ Um bom emprego e um lar, educação de boa qualidade para os filhos, um lugar de paz e sossego? São muitos os questionamentos e indagações que norteiam a temática da imigração, porém, todos os imigrantes estão com seus anseios permeados por sonhos e esperança.

Na última década, acentuou-se o fluxo de imigrantes no Brasil, por diversos motivos: guerras, catástrofes ambientais, perseguição 
religiosa, conflitos políticos, entre outros motivos. Conforme os dados divulgados pelo Relatório Anual OBMigra, há mais de 1 mi1hão de imigrantes no país, considerando todos os registros legais, predominando os fluxos oriundos da Venezuela, Haiti e Colômbia. (CAVALCANTI; OLIVEIRA; MACEDO, 2020)

A Lei $n^{\circ}$ 13.445/2017, conhecida como a Lei da Imigração, garante, no inciso VIII, o direito à reunião familiar do imigrante. (BRASIL, 2017) Sendo assim, os filhos e filhas dos imigrantes, paulatinamente, estão chegando ao nosso país, carregando consigo seus sonhos, seus medos e suas esperanças.

As prerrogativas legais do nosso país garantem à criança e ao adolescente, estrangeiro ou autóctone, o direito à educação, seu acesso e a permanência nos espaços escolares. A Constituição Federal de 1988, no art. 5º , estabelece igualdade de direitos entre brasileiros e estrangeiros. "Todos são iguais perante a lei, sem distinção de qualquer natureza, garantindo-se aos brasileiros e aos estrangeiros residentes no País a inviolabilidade do direito à vida, à liberdade, à segurança e à propriedade [...]". (BRASIL, 1988, p. 5, grifo nosso) O Estatuto da Criança e Adolescente (ECA), também assegura o direito à educação desses atores sociais. "A criança e o adolescente têm direito à educação, visando o pleno desenvolvimento de sua pessoa [...]" (BRASIL, 1990).

Segundo o Atlas Temático, em 2019, o Brasil registrava 100.079 estudantes imigrantes (BALTAR; BALTAR; BAENINGER, 2020) frequentando as escolas brasileiras, com suas histórias de vida, seu idioma e sua cultura, estabelecendo novos olhares, novos diálogos e práticas pedagógicas de acolhimento e inserção social nas instituições escolares.

Diante dos direitos dos imigrantes estabelecidos na legislação brasileira, tivemos a curiosidade em realizar uma investigação, de abordagem qualitativa do tipo Estado da Arte, tendo como problema de pesquisa a seguinte indagação: quais são os resultados das pesquisas acadêmicas, teses e dissertações, que tratam da imigração no período de 2013 a 2018 e quais destas enfatizam a importância da educação escolar para as crianças e adolescentes imigrantes? Para responder à esse questionamento, o artigo teve o objetivo de mapear e analisar os resultados das pesquisas acadêmicas, teses e dissertações dentro do recorte temporal mencionado, que abordaram a temática da imigração no Brasil, para identificar quais 
delas trataram do processo de escolarização para as crianças e adolescentes imigrantes.

O tipo de pesquisa estado da arte foi escolhido por ter o objetivo de contribuir para que os professores e pesquisadores tenham um panorama sobre a imigração no Brasil e as possíveis reverberações no processo de escolarização das crianças e adolescente imigrantes.

\section{Imigração e educação}

Migrar é um ato inerente ao ser humano. Desde os primórdios da história, os homens e mulheres migram, pois essa é a principal teoria que sustenta a expansão do humanidade sobre a face da Terra. Segundo os dados divulgados pela Organização Internacional para as Imigrações (OIM) estima-se que cerca de 272 milhões de migrantes internacionais residam em um país diferente daquele em que nasceram. (ORGANIZAÇÃO INTERNACIONAL PARA AS IMIGRAÇÕES, 2020)

Atualmente, estamos vivenciando novos fluxos migratórios, oriundos da entrada do Brasil na rota das migrações Sul-Sul (BAENINGER et al., 2018), inserindo-se no contexto das migrações internacionais do século XXI. (BAENINGER; PERES, 2017) Esse movimento se deve ao crescimento e a estabilidade econômica que o Brasil registrou em outros tempos, fato que atraiu imigrantes de todos os continentes. Nesse cenário, a chegada dos imigrantes - haitianos, africanos, venezuelanos, colombianos, e de outras nacionalidades - (re)configuram, (re)descobrem, (re)significam os espaços sociais e laborais, assim como as dinâmicas escolares de muitas salas de aula no nosso país.

Com a chegada dos filhos e filhas dos imigrantes, as instituições escolares deparam-se com mais um desafio: de acolhê-los e garantir seu acesso e permanência nos espaços escolares. André (2016, p. 59) salienta que "[...] há escolas que nem sempre reconhecem o direito do aluno, exigindo muitos documentos para os pais que, na maioria das vezes, não entendem o idioma local", esquecidas de que a educação é um direito de todos, brasileiro ou estrangeiro, garantido pela Constituição Federal do Brasil de 1998. (BRASIL, 1988)

A escolarização da criança e do adolescente imigrante, não se restringe somente à matrícula na escola, mas deve proporcionar às crianças e adolescentes imigrantes um espaço intercultural, no qual possam ter "vez" e "voz" no processo educativo. E, nesse 
sentido, as instituições escolares precisam estar atentas à esses novos alunos, propondo alternativas de acolhimento e integração, como também, viabilizar sua inserção escolar e social. Assim, estariam rompendo com uma proposta de educação homogeneizante, etnocêntrica (ROCHA, 1984), domesticadora (FREIRE, 2003) e bancária, de acordo com Freire (1970).

A criança e o adolescente, quando migram, não deixam de ser quem eram antes de migrar. Suas idiossincrasias, suas experiências, seu jeito de ver o mundo, suas esperanças e sonhos, os acompanham juntamente com seu material escolar. Pois, como já anunciava Paulo Freire (2014), não é possível realizar a "leitura da palavra" sem relacioná-la com a "leitura de mundo".

Para que aconteça esse movimento de ensino e de aprendizagem, o diálogo se apresenta como um convite, uma troca, um exercício de alteridade para, coletivamente, participarmos de construções, que constituem seres "criativos e re-criativos". É no debate e no embate que o diálogo se constrói, em uma atitude curiosa e participativa, questionar, argumentar e estimular "a pensar e repensar o pensamento do outro". (FREIRE; SHOR, 1986, p. 14) Nessa perspectiva, os estudantes imigrantes devem estar em constante interação com os alunos brasileiros e, por meio dos diálogos estabelecidos pelo professor e pela instituição escolar, aprenderão novas formas de ver o mundo, como também, ensinarão sua maneira de ver e estar no mundo.

Moreira e Candau (2003) salientam que a instituição escolar deve tornar a cultura um elemento central de seus planos e de sua prática, rompendo assim com uma visão monocultural, propondo práticas pedagógicas que lidem com a pluralidade de culturas e superem o daltonismo cultural.

Candau (2008) sugere em seus estudos uma educação intercultural, que possibilite uma prática pedagógica que favoreça o encontro entre culturas, que viabilize o diálogo entre os saberes, entre as formas de estar e ser no mundo.

Nessa perspectiva de construção de práticas pedagógica interculturais, todos os atores sociais são convidados à uma mudança de ótica, um novo olhar para o outro, reconhecendo as diferenças como uma riqueza a ser potencializada, como destaca Candau (2014), uma riqueza que se encontra no idioma, na cultura, na cor, nos gestos, nas singularidades do fazer e do ser. 


\section{Metodologia}

Como apresentado nas seções anteriores, o estudo sobre a imigração contemporânea apresenta-se como um fenômeno multifacetado. Para tanto, optou-se nesse estudo pela abordagem de pesquisa qualitativa do tipo estado da arte, porque este possibilita ao pesquisador uma visão geral do que está sendo pesquisado e permite identificar as contribuições e os avanços científicos de uma área do conhecimento.

As autoras Romanowski e Ens (2006, p. 39) salientam a importância das pesquisas do tipo Estado da Arte, onde é possível "[...] apreender a amplitude do que vem sendo produzido", com o intuito de "diagnosticar temas relevantes, emergentes e recorrentes, indicar os tipos de pesquisa, organizar as informações existentes bem como localizar as lacunas existentes". (ROMANOWSKI; ENS, 2006, p. 41)

Diante disso, fica evidente a imprescindibilidade desse tipo de pesquisa no campo educacional, para identificar os múltiplos enfoques e perspectivas na construção do conhecimento científico, a fim de provocar mudanças significativas na educação, pautadas na relação intrínseca da teoria com a prática.

Para a construção desse estudo, o levantamento ocorreu nas pesquisas acadêmicas, teses e dissertações, em buscas on-line, que abordassem o tema da imigração e a relação com o processo de escolarização das crianças e adolescentes imigrantes. Para a constituição do corpus de análise, recorremos ao Instituto Brasileiro de Informação em Ciência e Tecnologia (IBICT) na Biblioteca Digital Brasileira de Teses e Dissertações (BDTD). O mapeamento e a identificação de teses e dissertações ocorreram via plataforma digital.

O levantamento das pesquisas foi realizado utilizando a opção "busca avançada" com as palavras-chave "Imigração" e "Brasil" na BDTD. Já no mapeamento das produções acadêmicas de teses e dissertações, foi delimitado ao período de 2013 a 2018, pois, conforme Uebel (2015), acredita-se que nesse ínterim o Brasil vivenciou o boom imigratório, tornando-se como local de destino bem como de rota de um dos maiores fluxos imigratórios do globo terrestre.

A plataforma da BDTD apresentou 326 pesquisas realizadas em nível de mestrado e doutorado (Acadêmico e Profissional). O download dos arquivos ocorreu nos dias 4, 5 e 6 de outubro de 2019, sendo o material coletado separado em pastas restritas, uma para teses e outra para as dissertações. O material selecionado foi 
2 Para visualizar as teses e dissertações que foram utilizadas como corpus de análise é necessário acessar o link: https:// bit.ly/2WMJZCf

submetido a uma leitura crítica do título, do resumo, das palavras-chaves e da introdução, a fim de identificar e selecionar as que poderiam compor o corpus de análise. Feito esse processo, o corpus de análise restringiu-se a 63 pesquisas, ${ }^{2}$ sendo 49 dissertações de mestrado e 14 teses de doutorado que tratavam especificamente da imigração no Brasil.

O processo de análise das 63 pesquisas acadêmicas foi realizado na seção que trata das considerações finais destas, pois compreende-se que nesta parte do trabalho o autor-pesquisador retoma os objetivos da pesquisa, responde seu problema de pesquisa e evidencia os achados da investigação. A técnica de análise utilizada foi a Análise de Conteúdo (AC) diante da perspectiva de Bardin (2011).

Bardin (2011) menciona que a Análise de Conteúdo é realizada em três fases, sendo elas respectivamente, (a) pré-análise, (b) exploração do material e (c) tratamento dos resultados.

A pré-análise é a etapa da organização no qual se realiza o primeiro contato dos pesquisadores com os materiais, denominada por Bardin (2011) de leitura "flutuante". Estabelece-se um esquema de organização bem delimitado, porém flexível. Nesse momento, ocorre a escolha dos documentos que serão analisados, a formulação das hipóteses e dos objetivos.

Na etapa, exploração do material, realiza-se a exploração do corpus de análise. Bardin ressalta que essa etapa "[...] longa e fastidiosa, consiste essencialmente em operações de codificação, decomposição ou enumeração, em função de regras previamente formuladas[...]". (BARDIN, 2011, p. 131) Nessa fase, são escolhidas as unidades de codificação que, conforme a autora, é o momento de atribuir códigos aos fragmentos textuais ou qualquer outro material em forma de texto (BARDIN, 2011). Realiza-se a codificação do material para posteriormente classificar e categorizar. A categorização é composta pelo agrupamento das informações, os pesquisadores debruçam-se a captar o sentido das comunicações, assim consolidando um significado.

Em conseguinte, a etapa do tratamento dos resultados baseia-se na condensação e no destaque das informações, resultando nas interpretações inferenciais. Essa etapa é onde "[...] os resultados brutos são tratados de maneira a serem significativos e válidos." 
(BARDIN, 2011, p. 131) A análise de Conteúdo objetiva fornecer indicadores elementares aos objetivos da pesquisa.

A seguir, apresenta-se as fases da Análise de Conteúdo que foram realizadas na investigação, conforme o Quadro 1.

Quadro 1: Fases da Análise de Conteúdo realizada nas considerações finais das

Teses e Dissertações

\begin{tabular}{|c|c|}
\hline Pré-análise & $\begin{array}{l}\text { As } 63 \text { pesquisas acadêmicas foram salvas em formato PDF, ar- } \\
\text { quivadas em pastas digitais e separadas com a denominação } \\
\text { (D) para Dissertações e (T) para Teses, cada pesquisa recebeu } \\
\text { um código e uma numeração, a exemplo D01 - Dissertação do } \\
\text { autor 01. Todos os códigos foram registrados em uma plani- } \\
\text { lha no Microsoft Word, contendo: título, ano da defesa, área } \\
\text { do conhecimento, cidade da instituição de ensino, cidade da } \\
\text { pesquisa, nacionalidade do imigrante, local da pesquisa e se } \\
\text { abordou o processo de escolarização da criança e do adoles- } \\
\text { cente imigrante. }\end{array}$ \\
\hline $\begin{array}{l}\text { Fase } 2 \text { - } \\
\text { Exploração do } \\
\text { Material }\end{array}$ & $\begin{array}{l}\text { Foram lidas com profundidade as considerações finais das } 63 \\
\text { pesquisas acadêmicas e os fragmentos textuais que apresen- } \\
\text { tavam os resultados das pesquisas que foram selecionadas } \\
\text { para serem codificados meticulosamente. }\end{array}$ \\
\hline $\begin{array}{l}\text { Fase } 2 \text { - } \\
\text { Codificação }\end{array}$ & $\begin{array}{l}\text { Os pesquisadores realizaram a leitura dos fragmentos textuais } \\
\text { retirados das pesquisas acadêmicas e criaram para estes } \\
\text { um código que representa o sentido semântico do fragmento } \\
\text { textual. Entende-se por códigos um sistema de símbolos que } \\
\text { permite a identificação de informações. Para tanto, nessa in- } \\
\text { vestigação foram criados } 31 \text { códigos. }\end{array}$ \\
\hline Fase 2 - & $\begin{array}{l}\text { Na categorização, ocorreu a união dos códigos criados que } \\
\text { eram iguais e/ou que se repetiram no processo de análise a } \\
\text { partir da semelhança semântica. }\end{array}$ \\
\hline $\begin{array}{l}\text { Fase } 3 \text { - } \\
\text { Tratamento dos } \\
\text { Resultados: } \\
\text { Análise de } \\
\text { Conteúdo }\end{array}$ & $\begin{array}{l}\text { Após o procedimento de codificação e categorização foi } \\
\text { possível identificar os códigos que tiveram maior incidência } \\
\text { perante as pesquisas analisadas, sendo eles os seguintes: } \\
\text { a) aspectos negativos na inserção social do imigrante, e b) } \\
\text { aspectos positivos na inserção social dos imigrantes. Os dois } \\
\text { códigos com maior incidência foram submetidos a três proce- } \\
\text { dimentos que objetivam preservar o rigor da Análise de Conte- } \\
\text { údo, sendo eles: 1) leitura crítica dos fragmentos retirados das } \\
\text { pesquisas acadêmicas; } 2 \text { ) identificação e criação dos grupos } \\
\text { de categorias em consonância ao sentido interpretativo dos } \\
\text { fragmentos; e 3) criação das categorias que emergiram dos } \\
\text { dois códigos analisados. As categorias que emergiram partem } \\
\text { da interpretação dos pesquisadores permitindo identificar o } \\
\text { Estado da Arte da produção científica em relação a imigração } \\
\text { no Brasil. }\end{array}$ \\
\hline
\end{tabular}

Fonte: elaboração dos autores.

revista entreideias, Salvador, v. 10, n. 2, p. 49-69, maio/ago. 2021 
Na seção seguinte, apresentamos os resultados da análise qualitativa a partir da técnica de Bardin (2011) que foi realizada nas pesquisas acadêmicas conforme a descrição apresentada no Quadro 1.

\section{Análise dos Dados e Resultados}

Como foi mencionado, os dois códigos que tiveram maior incidência diante da análise realizada são: a) aspectos negativos na inserção social do imigrante, e b) aspectos positivos na inserção social dos imigrantes.

Na sequência, são apresentados dois quadros que apresentam fragmentos textuais retirados das considerações finais das teses e dissertações, com o intuito de justificar e exemplificar as categorias que emergiram.

O código referente aos "Aspectos negativos na inserção social do imigrante", obteve 61 incidências que estiveram presentes nas pesquisas acadêmicas analisadas. Conforme o Quadro 02, apresenta-se as categorias que foram criadas a partir do código analisado.

Quadro 2 - Alguns resultados explicitados nas pesquisas para justificar o código aspectos negativos na inserção social do imigrante

\begin{tabular}{|l|l|}
\hline CATEGORIAS & TESE E DISSERTAÇÃO \\
\hline Categoria - Racismo, preconceito, xenofobia e estigmas & $\begin{array}{l}\text { Quantidade de } \\
\text { incidência: } 30\end{array}$ \\
\hline $\begin{array}{l}\text { "Este grupo imigrante é estigmatizado pela população } \\
\text { local que se vê ameaçada e pensa estar sendo invadida } \\
\text { devido ao fato de um grande contingente de imigrantes } \\
\text { simplesmente surgirem repentinamente na cidade". }\end{array}$ & D 11, p. 158 \\
\hline $\begin{array}{l}\text { "Identificaram entre os brasileiros a existência do racismo, } \\
\text { cuja manifestação é demonstrada por meio de gestos, } \\
\text { frases indiretas, atitudes injustificáveis, espaços cultural- } \\
\text { mente delimitados [..]". }\end{array}$ & D 22, p. 81 \\
\hline $\begin{array}{l}\text { Categoria - Falta de políticas públicas e legislações efeti- } \\
\text { vas para a população imigrante }\end{array}$ & $\begin{array}{l}\text { Quantidade de } \\
\text { incidência: } 17\end{array}$ \\
\hline $\begin{array}{l}\text { "Ouço que os imigrantes, em especial o público estudado, } \\
\text { os bolivianos, não estão incluídos no sistema de garantia } \\
\text { de direitos. Quando delineio o perfil e as problemáticas } \\
\text { trazidas por eles, fica evidente [...] a ausência de políticas } \\
\text { públicas". }\end{array}$ & T 06, p. 123 \\
\hline
\end{tabular}




\begin{tabular}{|c|c|}
\hline $\begin{array}{l}\text { "Embora haja um reconhecimento crescente da migração } \\
\text { como um problema social, que merece atenção e inter- } \\
\text { venção pública [...] a ausência de um plano nacional, [...] } \\
\text { que crie diretrizes e obrigatoriedades de ação aos entes } \\
\text { federados e seus atores, interfere para que o movimento } \\
\text { migratório seja um processo difícil não apenas no seu tra- } \\
\text { jeto de deslocamento, mas na regularização e integração } \\
\text { no Brasil". }\end{array}$ & D 41 , p. 128 \\
\hline $\begin{array}{l}\text { Categoria - Trabalho escravo ou análogo à escravidão, mal } \\
\text { remunerado e em condições precárias }\end{array}$ & $\begin{array}{l}\text { Quantidade de } \\
\text { incidência: } 14\end{array}$ \\
\hline $\begin{array}{l}\text { "Pontualmente acerca do trabalho na costura, indicamos } \\
\text { que ao longo das três últimas décadas, [..] as condições } \\
\text { de trabalho reconhecidamente degradantes no interior das } \\
\text { oficinas não foram essencialmente alteradas". }\end{array}$ & D 03, p. 128 \\
\hline $\begin{array}{l}\text { "O fato dos imigrantes ter acesso a uma habitação e mui- } \\
\text { tas vezes uma maneira de romper com formas de explora- } \\
\text { ção e relações de dependência com o patrão, condições } \\
\text { às quais se submetem no momento de aceitar vir no país } \\
\text { com facilidades de comida e moradia em troca de trabalho } \\
\text { excessivo e mal remunerado". }\end{array}$ & D 07, p. 161 \\
\hline
\end{tabular}

Fonte: elaboração dos autores.

No Quadro 2, foi possível identificar três categorias que emergiram do código analisado "aspectos negativos na inserção social do imigrante". A categoria "racismo, preconceito, xenofobia e estigmas" apresentou 31 incidências diante das pesquisas analisadas. O imigrante, em seu "sonho brasileiro", depara-se com muitas dificuldades no processo de inserir-se na nova terra. O novo idioma, a adaptação cultural, a burocratização da documentação, o emprego, a moradia e, como revelado nas pesquisas acadêmicas, o preconceito e a discriminação.

Os dados apontam que o imigrante no Brasil é alvo constante de ataques xenófobos, discriminatórios e racistas. Infere-se que uma "parte da sociedade brasileira" se sente ameaçada com a presença dos imigrantes no país, inflando discursos ardilosos e praticando ações reducionistas e estigmatizante, culpabilizando as ádvenas pelos problemas sociais no país, como a saúde pública deficitária, o desemprego e o aumento da criminalidade, o que leva a atitudes de repulsa e ódio.

As pesquisas acadêmicas demonstraram que o racismo, ora velado, ora explícito, não se manifesta de maneira igual para os imigrantes, tendendo a agravar-se quando o imigrante é negro e/ ou sua origem é um país "pobre". O racismo no Brasil se efetiva por meio de padrões e preceitos discriminatórios raciais que são 
normalizados na e pela sociedade, difundindo-se nos espaços políticos, econômicos e sociais. (ALMEIDA, 2018) Porém, o imigrante em solo brasileiro enfrenta o racismo e outras discriminações, que denomina-se como o "novo racismo".

O novo racismo caracteriza-se pela dominação por meio da exclusão ou da exploração que "[...] tolera o diferente, mas somente na medida em que este se mantenha distante, segregado e excluído". (DIEHL, 2017, p. 56) O autor salienta que o cerne deste novo racismo se apresenta nas diferenças culturais, com o objetivo de segregar o outro grupo, neste caso, o imigrante. (DIEHL, 2017)

O segundo código "Aspectos positivos na inserção social do imigrante", apresentou 26 incidências. Conforme o Quadro 3, apresenta-se as categorias que foram criadas a partir do código analisado.

Quadro 3 - Alguns resultados explicitados nas pesquisas para justificar o código aspectos positivos na inserção social do imigrante

\begin{tabular}{|c|c|}
\hline CATEGORIAS & $\begin{array}{l}\text { TESE E } \\
\text { DISSERTAÇÃO }\end{array}$ \\
\hline Categoria - Rede de apoio e solidariedade ao imigrante & $\begin{array}{l}\text { Quantidade de } \\
\text { incidência: } 16\end{array}$ \\
\hline $\begin{array}{l}\text { "Uma rede muito importante a destacar é a rede da aco- } \\
\text { Ihida, desde o Acre. Os imigrantes haitianos relatavam a } \\
\text { presença da Pastoral Migratória e o papel das Igrejas e de } \\
\text { voluntários da sociedade civil. As igrejas (católica e protes- } \\
\text { tante), [...] foram cruciais na chegada desses imigrantes ao } \\
\text { Rio Grande do Sul, [...]". }\end{array}$ & D 17, p.188 \\
\hline $\begin{array}{l}\text { "[...] verifica-se que a proteção social do imigrante é reali- } \\
\text { zada principalmente - e quase que exclusivamente - pela } \\
\text { atuação de professores e alunos em projetos e cursos de } \\
\text { extensão desenvolvidos por Universidade [...]". }\end{array}$ & D 19, p.124 \\
\hline Categoria - Valorização da sua cultura, idioma e identidade & $\begin{array}{l}\text { Quantidade de } \\
\text { incidência: } 10\end{array}$ \\
\hline $\begin{array}{l}\text { "Se por um lado esses imigrantes puderam perceber as } \\
\text { mazelas do seu país, por outro, o estar fora significou re- } \\
\text { descobrir e valorizar a africanidade, afirmando, desta forma, } \\
\text { a identidade africana e angolana em terras estrangeiras". }\end{array}$ & D 02, p. 170 \\
\hline $\begin{array}{l}\text { "A imigração, mesmo forçada, trouxe aos entrevistados no- } \\
\text { vas possibilidades identitárias, que foram construídas com } \\
\text { mais autonomia e consciência política e tomaram possível o } \\
\text { desenvolvimento de fragmentos emancipatórios". }\end{array}$ & D 15, p. 160 \\
\hline
\end{tabular}

Fonte: elaboração dos autores. 
No Quadro 3 foi possível identificar que a categoria "rede de apoio e solidariedade ao imigrante" apresentou 16 incidências diante das pesquisas analisadas. Infere-se assim que "outra parcela da sociedade brasileira", acolhe, abraça e orienta o imigrante em sua nova terra e na defesa dos seus direitos humanos.

As pesquisas acadêmicas revelaram uma rede de acolhimento, de apoio e solidariedade, destinada aos imigrantes em seu processo migratório. Essa rede é formada pela sociedade civil, por ONGs, igrejas e universidades. É mister salientar que a Missão Paz ${ }^{3}$ e a Pastoral do Imigrante, ${ }^{4}$ foram ressaltadas na maioria das pesquisas, como atuantes no acolhimento e na defesa dos direitos humanos dos imigrantes.

$\mathrm{Na}$ falta de políticas públicas e ações efetivas do Estado no que tange o acolhimento e inserção social do imigrante, as redes de solidariedade e apoio ofereceram às ádvenas alguns serviços como: a): hospedagem temporária, alimentação, saúde e assistência social; b): procedimentos de regularização documental, acesso ao mercado de trabalho e orientações em seus direitos legais; c): aulas de língua portuguesa.

Continguiba e Continguiba (2014, p. 66) ressaltam que "o exercício de alteridade é uma via de duas mãos de seres que se pretendem sociais e sociáveis, é troca de empatia. É necessário estarmos aptos para um movimento duplo, o de autopercepção e o da percepção do outro". Nesse movimento de duplicidade e de percepção do outro, as redes de acolhimento, que se estabeleceram em todo o país, proporcionaram aos imigrantes ações revestidas de altruísmo, empatia e alteridade.

A partir da análise realizada nas 63 pesquisas acadêmicas, foi possível também identificar a quantidade de pesquisas publicadas por diferentes instituições de ensino superior no Brasil e suas respectivas regiões. O Quadro 4 realiza um detalhamento sobre esses itens que abordam a temática desse artigo, a imigração no Brasil.
3 A Missão Paz é uma instituição filantrópica pertencente aos missionários Scalabrianos, que concede apoio e acolhimento a imigrantes e refugiados na cidade de São Paulo. Possuem a Casa do Imigrante, um abrigo que tem a capacidade para acolher 110 imigrantes. Ver mais em: http:// www.missaonspaz.org/menu/ quem-somos

4 O Serviço Pastoral dos Migrantes é uma ação da igreja Católica, que tem como centralidade a acolhida do imigrante e a defesa dos seus direitos, independente da raça, credo, cultura ou gênero. Ver mais em https://spmigrantes.wordpress. com/quem-smos/ 
Quadro 4 - Quantitativo de pesquisas por IES (2013 -2018)

\begin{tabular}{|c|c|c|c|}
\hline Regiões & IES & Quantidade & \\
\hline \multirow[t]{4}{*}{ Nordeste } & Universidade da Paraíba (UFPB) & 01 & \multirow[t]{4}{*}{04} \\
\hline & Universidade de Fortaleza (Unifor) & 01 & \\
\hline & Universidade Federal de Pernambuco (UFPE) & 01 & \\
\hline & Universidade Federal do Ceará (UFC) & 01 & \\
\hline \multirow[t]{8}{*}{ Sul } & $\begin{array}{l}\text { Universidade Federal do Rio Grande do Sul } \\
\text { (UFRGS) }\end{array}$ & 09 & \multirow[t]{8}{*}{19} \\
\hline & Universidade Federal de Santa Catarina (UFSC) & 04 & \\
\hline & $\begin{array}{l}\text { Universidade do Extremo Sul de Santa Catarina } \\
\text { (Unesc) }\end{array}$ & 01 & \\
\hline & Universidade do Sul de Santa Catarina (Unisul) & 01 & \\
\hline & Universidade Estadual de Ponta Grossa (UEPG) & 01 & \\
\hline & Universidade Estadual do Paraná (Unespar) & 01 & \\
\hline & Universidade Federal de Pelotas (UFPEL) & 01 & \\
\hline & Universidade Federal de Santa Maria (UFSM) & 01 & \\
\hline \multirow[t]{11}{*}{ Sudeste } & Universidade de São Paulo (USP) & 10 & \multirow[t]{11}{*}{29} \\
\hline & $\begin{array}{l}\text { Pontifícia Universidade Católica de São Paulo } \\
\text { (PUC-SP) }\end{array}$ & 08 & \\
\hline & Universidade Federal do ABC (UFABC) & 03 & \\
\hline & Universidade Presbiteriana Mackenzie & 01 & \\
\hline & Fundação Oswaldo Cruz (Fiocruz) & 01 & \\
\hline & Fundação Getúlio Vargas (FGV) & 01 & \\
\hline & Universidade Estadual Paulista (Unesp) & 01 & \\
\hline & Universidade Estadual de Campinas (Unicamp) & 01 & \\
\hline & Universidade do Estado do Rio de Janeiro (UERJ) & 01 & \\
\hline & Universidade Federal de São Carlos (UFSCAR) & 01 & \\
\hline & Universidade Nove de Julho (UNINOVE) & 01 & \\
\hline \multirow{4}{*}{$\begin{array}{l}\text { Centro- } \\
\text {-Oeste }\end{array}$} & Universidade de Brasília (UnB) & 08 & \multirow[t]{4}{*}{11} \\
\hline & Universidade Federal de Goiás (UFG) & 01 & \\
\hline & Universidade Federal da Grande Dourados (UFGD) & 01 & \\
\hline & $\begin{array}{l}\text { Pontifícia Universidade Católica de Goiás (PUC- } \\
\text { Goiás) }\end{array}$ & 01 & \\
\hline \multicolumn{3}{|c|}{ Total de Pesquisas (Dissertações e Teses) } & 63 \\
\hline
\end{tabular}

Fonte: elaboração dos autores.

A partir do Quadro 4, é possível identificar que a região sudeste, com 29 pesquisas, no período de 2013 até 2018, foi a região que mais publicou pesquisas acadêmicas sobre a temática de imigração no Brasil, representando um total de $46 \%$ das pesquisas analisadas. É importante destacar que essa região concentra o maior número de imigrantes no país. Segundo os dados da Polícia Federal no ano de 2019, o estado de São Paulo registrou 550.890 imigrantes, seguido 
pelo estado do Rio de Janeiro, com 168.562 registros ativos na Polícia Federal. (BRASIL, 2019)

Em seguida, a Região Sul do país publicou 19 pesquisas que tratam de imigração no Brasil. A Universidade Federal do Rio Grande do Sul (UFRGS) concentra o maior número de pesquisas acadêmicas publicadas na região sul. A Região Centro-Oeste apresenta 11 pesquisas, sendo oito destas representadas pela Universidade de Brasília (UnB). A Região Norte não possui pesquisas acadêmicas publicadas que tratam da temática desse artigo.

A pesquisa deste artigo também teve o objetivo de identificar quais das 63 pesquisas acadêmicas analisadas tratam do processo de escolarização para as crianças e adolescentes imigrantes. A partir da análise realizada foi possível identificar que somente 05 pesquisas acadêmicas, sendo uma tese (T10) e quatro dissertações (D01, D16, D27, D35), tratam da imigração no Brasil e investigam o processo de escolarização para crianças e adolescentes imigrantes, investigações essas que foram desenvolvidas na cidade de São Paulo.

A seguir, apresenta-se uma síntese das investigações com o intuito de entender como esses atores sociais são abordados nas pesquisas e a relação da educação com a imigração.

A pesquisa D01, "Relações interculturais no espaço escolar: estudo etnográfico de alunos bolivianos na rede pública de ensino paulistana", defendida no ano de 2016, objetivava analisar as relações sociais que acontecem entre alunos bolivianos, alunos brasileiros e os educadores no ambiente escolar.

A autora concluiu que há "diversas falhas" no processo de inclusão das crianças bolivianas no ambiente escolar, destacando a dificuldade do idioma. Constatou, também, que as crianças não compreendem os professores e os colegas brasileiros, resultando em timidez, insegurança e invisibilidade. A autora salienta a questão do preconceito e discriminação que as crianças bolivianas sofrem no ambiente escolar. A autora ressalta que a instituição escolar precisa repensar a forma como está promovendo a inserção desses estudantes e sugere que adotem a perspectiva intercultural, pois acredita que é um elemento fundamental na desconstrução de estigmas e na construção de uma sociedade mais democrática. (SILVA, 2016)

A pesquisa D16, "Interculturalidade na educação brasileira: a inserção de bolivianos em escolas públicas estaduais", publicado no ano de 2014, teve como objetivo analisar a interculturalidade 
na educação, tendo como referência as propostas de Paulo Freire de educação como cultura. A autora conclui que, após examinar as práticas pedagógicas dos professores nas escolas pesquisadas, com um número expressivo de alunos bolivianos e descendentes de imigrantes bolivianos, há a falta de preparo para atender às demandas da nova realidade. Aponta que o poder público e a escola devem assumir a realidade dos fenômenos migratórios e seus novos alunos. Propõe uma educação problematizadora, que considere a leitura do mundo de sua comunidade, o diálogo intercultural e o reconhecimento do valor dos diferentes saberes. (GONÇALVES, 2014)

A pesquisa acadêmica D27, intitulada "A inserção de alunos imigrantes africanos negros na rede estadual de ensino na cidade de São Paulo (2014-2016)", defendida em 2016, descreveu e avaliou como se estrutura a inserção dos alunos africanos no cotidiano escolar, identificando as relações que se estabelecem entre os alunos imigrantes negros, os outros alunos, os professores, os gestores e os demais funcionários da escola, bem como as relações entre as culturas no ambiente escolar. A autora ressalta que no contexto do sistema estadual de ensino de São Paulo, não são atendidas as especificidades dos alunos imigrantes. A inclusão promovida por esse sistema se dá apenas com a efetivação da matrícula, porém, não existe um acompanhamento pedagógico para esses alunos. (ROSA, 2016)

Constatou que os alunos imigrantes ficam geralmente isolados, ou apenas com seus pares de nacionalidade. As relações entre imigrantes e não imigrantes são conflituosas, principalmente quanto ao respeito, à valorização e ao significado da cultura. A autora relatou episódios de violência física e psicológica entre alunos imigrantes e não imigrantes, como também atos de racismo, preconceito e discriminação. A autora reitera o papel da escola em garantir a diversidade étnica e a construção de caminhos para reconhecer, respeitar e valorizar o outro. (ROSA, 2016)

Em seguida, a pesquisa D35, com o título "A voz de estudantes Bolivianos em uma escola pública da cidade de São Paulo", defendida no ano de 2015, objetivou compreender, por meio da voz dos estudantes bolivianos, como se estabeleceu sua inserção na escola brasileira. A autora constatou que os adolescentes imigrantes bolivianos sonham com a formação educacional, contudo, deparam-se com diversas adversidades no novo país, como as rejeições de origem étnica, de classe, cultural e a falta de documentação adequada. 
Salienta que os dados demonstram que a escola constitui um dos espaços mais importantes no cotidiano do adolescente imigrante e se torna, também, um dos primeiros lugares a disseminar as formas de violência simbólica, epistemológica ou física. (ALVES, 2015)

Na pesquisa T01, intitulada "Narrativas silenciosas: identidade e imigração na educação infantil”, a autora aborda como o processo de hibridização cultural de uma criança imigrante na educação infantil.

A partir dos resultados obtidos na pesquisa, Santos (2018) conclui que os processos identitários de crianças em contexto de imigração se efetuam em três categorias; 1) Diferenciação horizontal: descreve o papel da interação entre os pares na hibridização identitária das crianças no contexto da imigração, estabelecendo diferenças entre si, muitas vezes fundamentadas em padrões presentes na sociedade e pelos interesses particulares que regem as interações infantis; 2) Diferenciação hierárquica: os diferentes status que são conferidos à criança imigrante, dependendo do imaginário que se tem a respeito do seu país de origem, no país que se estabelece - a autora salienta que no âmbito da educação infantil, a diferenciação hierárquica se dá nas relações entre a instituição escolar e a comunidade; 3) Diferenciação Diaspórica: movimento impulsionado pelo "sair de si" em direção à diferença do outro. A autora ressalta que essa diferenciação pode ser vivida por todos os que se relacionam com a criança no contexto da imigração. (SANTOS, 2018)

\section{Considerações Finais}

Este artigo teve o objetivo de mapear e analisar os resultados das pesquisas acadêmicas, teses e dissertações, publicadas nos anos de 2013 a 2018, que abordaram a temática da imigração no Brasil, e identificar quais destas trataram do processo de escolarização para as crianças e adolescentes imigrantes.

A partir da técnica de análise de dados retirados do texto das considerações finais das pesquisas acadêmicas, teses e dissertações, foi possível identificar os aspectos negativos da inserção social do imigrante, onde as seguintes categorias emergiram: a) racismo, preconceito, xenofobia e estigmas; b) falta de políticas públicas e legislações efetivas para a população imigrante; e c) trabalho escravo ou análogo à escravidão, mal remunerado e em condições precárias. A categoria que teve maior incidência foi referente ao racismo, preconceito, xenofobia e estigmas, revelando que os 
resultados das pesquisas acadêmicas expõem que os imigrantes sofrem todos essas mazelas conforme a categoria indicada.

No código "aspectos positivos da inserção social do imigrante", as categorias que emergiram foram: a) rede de apoio e solidariedade ao imigrante; e b) valorização da sua cultura, idioma e identidade. A categoria "rede de apoio e solidariedade ao imigrante", com maior número de incidências nesse código, revelaram que uma parcela da sociedade brasileira, acolhe, integra e se torna ponte para a efetivação dos direitos humanos dos imigrantes.

Apesar do nosso país ser pluri e multicultural, caracterizado pela diversidade resultante de um processo histórico marcado pela miscigenação de povos, a partir das pesquisas acadêmicas investigadas, foi possível constatar que ser imigrante no Brasil é ser considerado como os "de fora". É deparar-se com diversas barreiras, preconceitos e discriminação, é lutar diariamente pelo seu espaço e pelo direito de "ser e estar" em uma nova terra. Infere-se também que muitos imigrantes sofrem racismo pela cor da sua pele, preconceito, estigmas e xenofobia pelas suas diferenças étnicas, linguísticas e geográficas.

A pesquisa revelou que a falta de políticas públicas favorece o acirramento dessas diferenças, reforçando a discriminação e o preconceito em nosso país, como também, o trabalho escravo e análogo à escravidão. O acolhimento do imigrante é uma obrigação à luz dos Direitos Humanos, no qual o Brasil é signatário e, portanto, as políticas públicas poderiam diminuir as barreiras, garantindo o bem-estar para os imigrantes, evitando situações de marginalizações pela falta de trabalho e eventuais casos de preconceito, xenofobia e estigmatização.

Os dados também revelaram que outra parcela da sociedade receptora estabelece redes de solidariedade e apoio à população imigrante, no acolhimento na nova terra e na orientação de seus direitos. Outrossim, evidencia-se que a valorização do idioma, da cultura e da identidade do imigrante se intensificam após o percurso migratório. Observa-se nesse sentido, que os imigrantes procuram novos espaços para que possam demonstrar sua cultura, seu idioma e socializar-se com seus irmãos conterrâneos.

O estado da arte revelou que há uma grande lacuna nas pesquisas acadêmicas referente ao processo de escolarização das crianças e adolescentes imigrantes, evidenciando um campo emergente de 
pesquisa que proporcione "vez" e "voz" a esses atores sociais em seu processo escolar.

Diante dos dados analisados, foi possível identificar as pesquisas que tratam do processo de escolarização para as crianças e adolescentes imigrantes. Das 63 pesquisas acadêmicas que compuseram o corpus de análise, somente cinco pesquisas - quatro dissertações de mestrado e uma tese de doutorado - investigaram o processo de escolarização para crianças e adolescentes imigrantes.

As pesquisas revelaram que a criança e o adolescente imigrante, assim como os adultos, são vítimas de racismo, preconceito e discriminação. Foram relatadas situações de violência simbólica, física e emocional que enfrentam no ambiente escolar. As pesquisas evidenciaram que a barreira linguística ocasiona estranhamento entre imigrantes e brasileiros, pois a comunicação não se estabelece e a socialização é prejudicada. Salienta-se, também, que a falta de políticas públicas e linguísticas reforçam a invisibilidade desse aluno imigrante.

A partir desse ponto, infere-se que o direito à educação aos imigrantes é garantido pela legislação brasileira, porém, limita-se somente à matrícula na escola. A inexistência de políticas públicas de acolhimento nas escolas brasileiras e a falta de ações direcionadas que considerem as especificidades desses alunos imigrantes, revelam o longo caminho que deve ser percorrido para que essa inclusão aconteça efetivamente.

Destaca-se que as instituições escolares devem proporcionar ações educativas que combatam o racismo, as discriminações e a invisibilidade social, na busca por igualdade e equidade. Nesse espaço, em que existe um leque de diversidades, a cultura deverá ser valorizada em uma proposta intercultural. É necessário romper com os silêncios curriculares, favorecendo ações e práticas pedagógicas para o respeito às diferenças, exigindo mudanças no currículo e um olhar atento na construção e execução do projeto político pedagógico.

Diante desse desafio, a construção de uma escola plural e democrática é possível, mas dependerá de reflexões e ações que culminem em novos olhares, novos diálogos e práticas educativas de acolhimento e inserção social. Nessa troca constante entre alunos imigrantes e brasileiros, a aprendizagem pode se efetivar no percurso formativo fundamentados na diversidade, alteridade e respeito pelo outro. 


\title{
Immigration in Brazil and the schooling process for immigrant children and adolescents
}

\begin{abstract}
This article presents an investigation of a qualitative approach through the state of the art type about immigration in Brazil and its relation with the schooling process of immigrant children and adolescents. The research aims to map and analyze the results of academic research, theses and dissertations published from 2013 to 2018 that addressed the topic on immigration in Brazil, in addition to identifying which of these dealt with the schooling process for immigrant children and adolescents. As an object of analysis, 63 researches were selected from the Digital Library of Theses and Dissertations, which were analyzed using the Content Analysis technique from the perspective of Bardin (2011). The data show that the immigrant is a victim of racism, prejudice, xenophobia and stigmas by a part of the receiving society and they are targets for the exploitation of labor, and are, sometimes, in situations of slavery or analogous to slavery. As a result, the lack of public policies and effective legislation aggravates this situation. The data also revealed that another part of the receiving society establishes networks of solidarity and support for the immigrant population, in welcoming them in the new land and guiding their rights. Furthermore, it is evident that the appreciation of the immigrant's language, culture and identity intensifies after the migratory journey. In relation to the schooling process of immigrant children and adolescents, the state of the art revealed restricted academic production, showing an emerging field of research, which provides immigrants with "opportunity" and "voice" in their schooling process.
\end{abstract}

Keywords: immigration; Brazil; schooling.

\section{La inmigración en Brasil y el proceso de escolarización de los niños y adolescentes inmigrantes}

\begin{abstract}
Resumen: Este artículo presenta una investigación de enfoque cualitativo del tipo estado del arte sobre la inmigración en Brasil y su relación con el proceso de escolarización de los niños, niñas y adolescentes inmigrantes. El objetivo de la investigación es mapear y analizar los resultados de investigaciones académicas, tesis y disertaciones publicadas de 2013 a 2018 que abordaron la inmigración en Brasil, además de identificar cuáles de estos trataron el proceso de escolarización para niños y adolescentes inmigrantes. Como objeto de análisis, se seleccionaron 63 estudios de la Biblioteca Digital de Tesis y Disertaciones, que se analizaron utilizando la técnica de Análisis de Contenido desde la perspectiva de Bardin (2011). Los datos muestran que el inmigrante es víctima de racismo, prejuicio, xenofobia y estigmas por parte de la sociedad receptora y son objetivos para la explotación laboral, y a veces se encuentran en situaciones de esclavitud o análogas a la esclavitud. Como resultado, la falta de políticas públicas y legislación efectiva agrava esta situación. Los datos también revelaron que otra parte de la sociedad receptora establece redes de solidaridad y apoyo para la población inmigrante, acogiéndoles en la nueva tierra y brindando orientación sobre sus derechos. Además, es evidente que la apreciación del idioma, la cultura y la identidad del inmigrante se intensifica después del viaje migratorio. En relación con el proceso de escolarización de niños, niñas y adolescentes inmigrantes,
\end{abstract}


el estado del arte reveló una producción académica restringida, mostrando un campo emergente de investigación, que brinda a los inmigrantes " oportunidad" y "voz" en su proceso de escolarización.

Palabras clave: inmigración; Brasil; enseñanza.

\section{Referências}

ALMEIDA, S. L. de. O que é racismo estrutural? Belo Horizonte: Letramento, 2018.

ALVES, M. A voz de estudantes Bolivianos em uma escola pública da cidade de São Paulo. 2015. Dissertação (Mestrado em Educação, Arte e História da Cultura) - Universidade Presbiteriana Mackenzie, São Paulo, 2015. Disponível em: http://tede.mackenzie.br/jspui/handle/ tede/1938. Acesso em: 18 nov. 2019.

ANDRÉ, B. P. A diversidade dos alunos estrangeiros e seu processo de adaptação em escolas brasileiras. In: BAHIA, J.; SANTOS, M. (org.). Um olhar sobre as diferenças: a interface entre projetos educativos e migratórios. São Paulo: Oikos, 2016. p. 56-78.

BAENINGER, R.; BOGUS, L. M.; MOREIRA, J. B.; VEDOVATO, L. R.; FERNANDES, Duval; SOUZA, M. R. de; BALTAR, C. S.; PERES, R. G.; WALDMAN, T. C.; MAGALHÃES, L. F. A. (org.). Migrações sul-sul. Campinas: Núcleo de Estudos de População "Elza Berquó" - Nepo/ Unicamp, 2018.

BAENINGER, R.; PERES, R. Migração de crise: a imigração haitiana para o Brasil. Revista Brasileira de Estudos da População. Belo Horizonte, v. 34, n. 1, p.119-143, jan./abr. 2017. Disponível em: http://www.scielo.br/pdf/ rbepop/v34n1/0102-3098-rbepop-34-01-00119.pdf. Acesso em: 24 fev. 2020.

BALTAR, C. S.; BALTAR, R.; BAENINGER, R. (coord.). Atlas temático; Observatório das Migrações em São Paulo, Observatórios das Migrações de Londrina, Migrações Internacionais, Região Sul. Campinas: Nepo/ Unicamp, 2020.

BARDIN, L. Análise de conteúdo. São Paulo: Edições 70, 2011.

BRASIL, [Constituição (1988)]. Constituição da República Federativa do Brasil. 18. ed. São Paulo: Saraiva, 1988.

BRASIL. Lei $n^{\circ}$ 8.069/90, de 13 de julho de 1990. Dispõe sobre o Estatuto da Criança e do Adolescente e dá outras providências. Brasília, DF: Presidência da República, Casa Civil, 1990. Disponível em: http://www. planalto.gov.br/ccivil_03/LEIS/L8069.htm. Acesso em: 16 out. 2018.

BRASIL. Lei $n^{0}$ 13.445, de 24 de maio de 2017. Institui a Lei de Migração. Brasília, DF: Presidência da República, Secretaria-Geral, 2017. Disponível em: http://www.planalto.gov.br/Ccivil_03/_ato20152018/2017/lei/113445.htm. Acesso em: 23 nov. 2019 
CANDAU, V. M. Direitos humanos, educação e interculturalidade: as tensões entre igualdade e diferença. Revista Brasileira de Educação, Rio de Janeiro, v. 13, n. 37, p. 45-56, jan./abr. 2008.

CANDAU, V. M. Educação Intercultural: entre afirmações e desafios. In: MOREIRA, A. F.; CANDAU, V. M. Currículos, disciplinas escolares e culturas. 2. ed. Petrópolis: Vozes, 2014. Cap. 1. p. 22-41.

CAVALCANTI, L.; OLIVEIRA, A. T. de; MACEDO, M. F. R. de. Imigração e refúgio no brasil: relatório anual 2020. Brasília, DF: OBMigra, 2020. Disponível em: https://portaldeimigracao.mj.gov.br/images/dados/ relatorio-anual/2020/Resumo\%20Executivo\%20_Relat\%C3\%B3rio\%20 Anual.pdf. Acesso em: 21 jan. 2021.

COTINGUiBA, M. L. P.; COTINGUiBA, G. C. Imigração haitiana para o Brasil: os desafios no caminho da educação escolar. Revista Pedagógica, Chapecó, v. 17, n. 33, p. 61-87, dez. 2014. Disponível em: https://bell. unochapeco.edu.br/revistas/index.php/pedagogica/article/view/2843. Acesso em: 13 dez. 2019.

DIEHL, F. Estrangeiro em uma terra estranha: racialização e estigmatização dos imigrantes haitianos em Lajeado, Rio Grande do Sul. 2017. Dissertação (Mestrado em Sociologia) - Universidade Federal do Rio Grande do Sul, Porto Alegre, 2017. Disponível em: https://lume. ufrgs.br/handle/10183/159143. Acesso em: 25 nov. 2019.

FREIRE, P. A importância do ato de ler: em três artigos que se completam. 45. ed. São Paulo: Cortez, 2003.

FREIRE, P. Ação cultural para a liberdade e outros escritos. Rio de Janeiro: Paz e Terra, 1982.

FREIRE, P.; SHOR, I. Medo e ousadia; O cotidiano do professor. Rio de Janeiro: Paz e Terra, 1986.

FREIRE, P. Pedagogia do oprimido. São Paulo: Paz e Terra, 1970.

FREIRE, P. Pedagogia dos sonhos possíveis. São Paulo: Terra, 2014.

GONÇALVES, A. L. N. Interculturalidade na Educação Brasileira: a inserção de bolivianos em escolas públicas paulistanas. 2014. Dissertação (Mestrado em Educação) - Universidade Nove de Julho, São Paulo, 2014. Disponível em: http://bdtd.ibict.br/vufind/Record/NOVE_9c683f 210f666cce835bb6f3e3c7f916. Acesso em: 18 nov. 2019.

MOREIRA, A. F. B.; CANDAU, V. M. Educação escolar e cultura(s): construindo caminhos. Revista Brasileira de Educação, Rio de Janeiro, n. 23, p. 156 - 170, maio/ago. 2003.

ORGANIZAÇÃO INTERNACIONAL PARA AS IMIGRAÇÕES (OIM). Informe sobre las Migraciones en el Mundo 2020. Disponível em: https:// publications.iom.int/system/files/pdf/wmr_2020_es_0.pdf. Acesso em: 24 fev. 2020.

ROCHA, E. P. G. O que é etnocentrismo? São Paulo. Editora Brasiliense. 1984. 
ROMANOWSKI, J. P.; ENS, R. T. As pesquisas denominadas do tipo "estado da arte" em educação. Revista Diálogo Educacional, Curitiba, v. 6, n. 19, p. 37- 50, set./dez. 2006. Disponível em: https://periodicos.pucpr. br/index.php/dialogoeducacional/article/view/24176/22872. Acesso em: 9 out. 2018.

ROSA, É. dos S. A inserção de alunos imigrantes africanos negros na rede estadual de ensino da cidade de São Paulo (2014-2016). 2016. Dissertação (Mestrado em Educação) - Pontifícia Universidade Católica de São Paulo, São Paulo, 2016. Disponível em: https://tede2.pucsp.br/handle/handle/19678. Acesso em: 18 nov. 2019

SANTOS, P. da S. Narrativas silenciosas: identidade e imigração na educação infantil. 2018. Tese (Doutorado em Educação) - Universidade de São Paulo, São Paulo, 2018. Disponível em: https://teses.usp.br/teses/ disponiveis/48/48134/tde-11122018-101037/pt-br.php. Acesso em: 28 nov. 2019.

SILVA, J. Relações Interculturais no Espaço Escolar: estudo etnográfico de alunos bolivianos na rede pública de ensino paulista. Estudo etnográfico de alunos bolivianos na rede pública de ensino paulista. 2016. Dissertação (Mestrado em Ciências Humanas e Sociais) - Universidade Federal do ABC, Santo André, 2016. Disponível em: http://bdtd.ibict. br/vufind/Record/UFBC_9b676ce99b22a33c6ea4037beccf3629.

Submetido em 25/05/2020

Aceito em 29/01/2021. 